\title{
MESENCEPHALITIS SYPHILITICA.
}

\author{
By S. A. KINNIER WILSON, London, AND STANLEY COBB, \\ Boston, Mass.
}

\section{INTRODUCTION.}

IT is a frequent occurrence in cases of neurosyphilis to find lesions in the midbrain; symptoms referable to this segment of the neuraxis are among the commonest in the disease-for example, the Argyll Robertson pupil and paralysis of the ocular muscles. But these symptoms are probably due in most instances to a relatively superficial inflammation, either leptomeningitis or ependymitis. The symptomatology of the cases discussed in the present paper suggests a deeper lesion, a true encephalitis of the midbrain, causing not only ocular palsies but tremor, and in two cases rigidity, of the paralysis agitans type. Recent pathological work both on Parkinson's disease ${ }^{1}$ and postencephalitic paralysis agitans ${ }^{2}$ has constantly demonstrated lesions in the midbrain, so the cases here presented are classified as mesencephalitis. It must be remembered, however, that certain lesions of the basal ganglia of the forebrain may produce paralysis agitans, hence the lesions causing the syndrome under discussion may be more widespread than the title of this paper would indicate. Moreover, it is important to bear in mind that arbitrary boundaries cannot well be drawn between the corpus striatum, the subthalamic region and the tegmentum of the midbrain, since the anatomical and physiological continuity of certain systems placed therein has been amply demonstrated. ${ }^{3,4}$

Most cases of tabes dorsalis and of dementia paralytica show involvement of the midbrain by presenting the Argyll Robertson pupil, but, curiously enough, the numerous published cases of 'tabes plus paralysis agitans' have usually been interpreted by their authors as mere coincidental associations of two distinct diseases. For example, Eshner ${ }^{5}$ (1909) says that locomotor ataxia and paralysis agitans can have little or nothing in common etiologically, anatomico-pathologically, or symptomatologically ; in short, he looks on the association of these two symptom-complexes as purely fortuitous. A glance at the diagnoses in the accompanying tabulation of the published cases will show that this was the prevailing opinion, especially in the pre-Wassermann days. Furthermore, most of the cases were published before anything was known concerning the pathology of paralysis agitans. Thus the earlier writers had no idea of the significance, from an anatomical standpoint, 
of the association of tremor or rigidity with the intra-ocular and extraocular palsies so often found in neurosyphilis. It seems worth while, therefore, to select for record four new cases of midbrain neurosyphilis, since there is recent and sufficient evidence for placing the lesion of the Argyll Robertson pupil (in the great majority of cases) in the midbrain, ${ }^{6,7}$ and for localizing (at least in part) the lesions which release the motor phenomena of tremor, chorea, athetosis and rigidity in the vicinity of the red nucleus, ${ }^{8,9}$ the substantia nigra, ${ }^{1,2}$ the corpus striatum, ${ }^{10}$ or in afferent or efferent tracts (which need not here be further described) coursing through the mesencephalon and regio subthalamica.

Wertheim Salomonson ${ }^{11}$ (1900) considered the combination of tabes with paralysis agitans a definite clinical entity, but he was inclined to place the lesions of paralysis agitans in the dorsal columns of the cord. He named his new syndrome 'Tromoparalysis tabioformis'-an elaborate title that one would hardly hope to see added to an already heavily burdened neurological nomenclature. This author also believed that paralysis agitans might have a syphilitic etiology. Nowadays it is easily proved by laboratory examinations of the blood and spinal fluid that such is not the case in most patients presenting the symptoms of Parkinson's disease, but a few cases have been proved to be syphilitic. Urechia ${ }^{12}(1921)$ found syphilitic lesions in the caudate and lenticular nuclei, most intense in the globus pallidus, in a case where the typical paralysis agitans syndrome appeared in a male general paralytic aged fifty-seven. The usual lesions of general paralysis were present in the cortex, but were less pronounced than those in the basal ganglia.

Recently a brain has been examined at the Department of Neuropathology of the Harvard Medical School which shows similar lesions. The case ${ }^{13}$ was that of a man who had a primary lesion at the age of thirty-six; seven years later he began to suffer from tremor, and at the age of forty-six was admitted to hospital as a case of paralysis agitans showing tremor of the face, arms and legs; the hands exhibited the typical 'pill-rolling' movements. Mental confusion and depression, with delusions and hallucinations, were remarked. The left pupil was irregular and smaller than the right ; neither reacted to light, but both contracted on convergence. The blood Wassermann test was positive ; the spinal fluid contained fifty-two cells per cubic millimetre, but its Wassermann reaction was negative (the patient had previously undergone intensive antisyphilitic treatment). A week after admission he died of an intercurrent pneumonia. Autopsy revealed broncho-pneumonia, pleurisy and aortitis. The brain showed the gross appearances of general paralysis-leptomeningitis, atrophy, ependymitis and adherent dura; the basal ganglia appeared normal to the naked eye. Microscopically, however, there was marked syphilitic inflammation of the corpus striatum, with great destruction of the large pallidal cells. 


\section{PREVIOUSLY RECORDED CASES.}

The first report made in medical literature of the occurrence of tabes or general paralysis with paralysis agitans is found in a paper by Ewald ${ }^{14}$ in 1877, describing a case of dementia paralytica with unilateral tremor of the paralysis agitans type ; the diagnosis of general paralysis was confirmed at autopsy. The next year Knessner ${ }^{15}$ described a somewhat similar case, also examined pathologically, but in neither of these is any adequate description given of the findings in the basal ganglia or midbrain. A graduation thesis by Anton Heimann ${ }^{16}$ (1888) describes two cases where tabes dorsalis was associated with paralysis agitans. Since then thirty-one cases have been mentioned in the literature ; twenty-two of these we have been able to trace, and they are briefly tabulated on page 47 , with the addition of our own four cases. Fourteen of the twenty-two were reported in the years 1888 to 1909, that is, in the period before the Wassermann reaction was in use, so the diagnosis of syphilis has to be sustained on clinical or pathological grounds. In nine the Argyll Robertson pupil gives good evidence, backed up in each case by either ataxia, absent knee jerks or optic atrophy. Two cases with fixed pupils showed absence of the knee jerks, one of them with marked ataxia. One patient had unequal pupils, and ataxic hypotonic legs. In one the condition of the pupils is not described, but autopsy revealed the typical cord lesions of tabes dorsalis. Thus it is satisfactorily proved that all thirteen had syphilis. Eleven of the patients also presented symptoms of paralysis agitans; one showed a rhythmic tremor of the foot, not described as Parkinsonian, and one had choreic movements. The average age of this group, however, is sixty, a time of life when paralysis agitans might well appear independently of the presence of syphilis. Of the eight cases recorded since 1914, four patients were so young as possibly to make Parkinson's disease unlikely (their ages being 34, 42, 46, and 53); three were older (56, 57 and 66), and in Archard's case the age was not given. In all of these eight, except de Massary's case, the clinical observations strongly suggested syphilis, and in five of them both the blood and spinal fluid gave positive Wassermann reactions. In Léri's case the Wassermann test was negative in both blood and spinal fluid, but this patient had root pains, keratitis, iritis and Argyll Robertson pupil-a convincing array of syphilitic symptoms. In the last case only one report on the spinal fluid is given, and although the Wassermann reaction was reported negative the presence of pleocytosis in the fluid, and the pathological diagnosis of dementia paralytica, practically brand this isolated finding of a negative Wassermann as a mistake. De Massary's case, on the other hand, although syphilis was diagnosed serologically, furnishes evidence that is rather deficient from the clinical and pathological stand- 


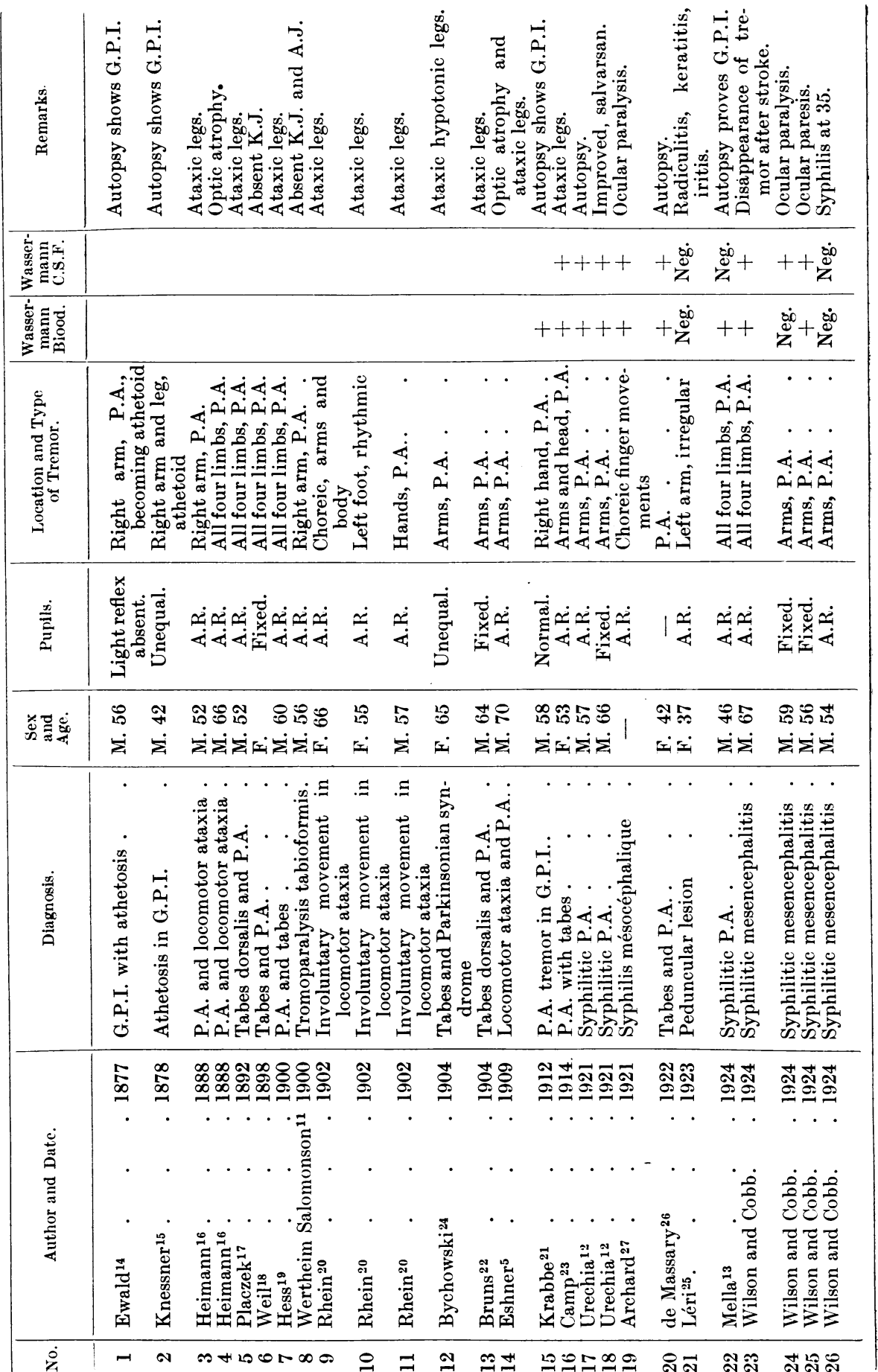


points, so it may be that his patient was a chronic tabetic who contracted epidemic encephalitis and thereafter developed the paralysis agitans syndrome. In Krabbe's case the spinal fluid was not examined, but autopsy revealed general paralysis.*

At the National Hospital, Queen Square, cases similar to those mentioned above have been not infrequently observed, so that it has been possible to collect in a few months the four recent cases reported herewith.

\section{PERSONAL CASES.}

\section{Case I.-Summary and Comment.}

A man of sixty-seven had right external strabismus for eight years, and for four years lightning pains in both legs, later in the arms and shoulders. For three years there had been stiffness in the legs with unsteady gait, and for two and a half years trembling of the legs. Tremor of the arms appeared.a few months later.

Physical examination on January 27, 1922, showed the following condition : masklike face, ptosis and external strabismus of the right eye. The pupils were unequal, irregular, and did not react to light, but contracted on convergence. There was a coarse tremor of both arms and legs, exaggerated by voluntary movement. The muscles were somewhat hypertonic, and all movements slow : there was general loss of muscular power. On the thorax there was hyperæsthesia to pain in the segmental areas from $D 4$ to $D 7$ on the right side, and D 1 to $\mathrm{D} 7$ on the left. The abdominal reflexes were absent, and on the left there was an extensor plantar, the right plantar being doubtful. The knee jerks were exaggerated, and patellar clonus was present. Control of the bladder was incomplete.

Blood Wassermann reaction, strongly positive; C.S.F. Wassermann, strongly positive.

In the course of 1922 a typical Parkinsonian gait and posture developed, and the tremor was more marked, becoming violent in January, 1924. In February there was a ' stroke' with coma for thirty-six hours, followed by right hemiparesis and partial aphasia. The tremor disappeared and had not recurred a month later, although voluntary motility largely returned. Physical examination on March 3, 1924, was similar to that of January, 1922, except that the paralysis of the right eye was more complete, tremor was absent, the right side was weak, and both plantar reflexes were extensor.

* Since this review of the literature was written a paper has been published by Gordon entitled " Epidemic Encephalitis and Syphilis : Differential Diagnosis" (Jour. Nerv. Ment. Dis., 1924, lix, 251). He reports a series of eighteen cases, six of which may be diagnosed as syphilitic mesencephalitis, a term which the author employs in contradistinction to epidemic encephalitis involving the midbrain. 
During 1922 a glance at this patient as he entered the examining room would satisfy one as to his Parkinsonism-gait, posture and tremor were all typical. Further examination, however, showed third nerve paralysis, A.R. pupils, areas of analgesia on the trunk. All these, with lightning pains, are tabetic symptoms and the first two are referable to the midbrain. The exaggerated reflexes and other signs of hemiplegia must be explained by vascular lesions. It is of great interest to note that the tremor stopped after the 'stroke,' referred to below in detail.

A. B., age sixty-five, fitter, was admitted to hospital on January 27, 1922, with a diagnosis of tabes and paralysis agitans. He dènied venereal disease.

Present Illness.-Over two years ago he began to be troubled with pains in both thighs. These were shooting, sharp, sometimes 'lightning-like' in character, and varied in severity, being usually worse in damp weather and particularly troublesome during the night. The pains gradually began to affect all the limbs. About a year after the onset of the pains weakness in both legs slowly developed, with stiffness in and near the joints ; as a result walking became difficult and unsteady. The weakness showed a tendency to progress slowly, and coincident with this some wasting in thighs and calves was noticed. More recently the legs began to 'tremble' below the knee joints, the right being first affected. Later a similar tremor, especially in the muscles of the upper arm, manifested itself, and a certain amount of loss of power in the right arm developed.

Various parresthesia were also complained of, especially numbness in the right arm and fingers, and in the thighs of both legs.

There had been some urinary derangement for a number of years.

The vision of the right eye had always been somewhat defective; a 'cast' in the eye had been present for perhaps five or six years. Within the last twelve months vision had been failing noticeably in both eyes, and a drooping of the right upper eyelid had gradually come on. Diplopia of some months' duration was also remarked.

\section{State on Admission.}

Nervous System.--Intelligence average. Patient seems unemotional, and of a phlegmatic disposition. Memory is fair, but not so good as it once was. Speech : articulation and phonation seem normal, although voice is somewhat monotonous.

Cranial Nerces.-2. Fields full to rough test. Fundi : both appear normal.

3, 4, 6. Ocular movements good ; no nystagmus. Diplopia complained of, especially on looking to right. Slight divergent strabismus. Right palpebral fissure smaller than left. Right ptosis, varying in degree.

Pupils : Slight inequality. Left larger than right; irregular in outline; both immobile to light, but react on accommodation. No consensual reflexes obtained.

voL. v. -No. 17 . 
Motor System.-On voluntary effort coarse tremor is observed in both upper and lower extremities, and occasionally in head in a lesser degree. The tremor in the legs is chiefly noticeable in the thighs on both sides. It is much less marked and often altogether absent when patient is at rest. Gait is slow and shuffling. Patient shows disinclination to move, and movements are accomplished slowly and laboriously.

Upper extremities : Grasp fair in both. There is a general diminution in power at all the joints, more marked on right, but no complete paralysis. No atrophy in the muscles, which are rather hypertonic. No incoordination.

Lower extremities : No complete paralysis of any muscle or group of muscles; a certain amount of generalised weakness and stiffness. Patient states thighs and calves are much smaller than formerly. No incoordination.

Bladder sphincter is weak; rectal control is good.

Sensory System.-Subjective: Numbness in right arm and fingers and in left hand.

Objective : Pin-prick diminution in areas represented by $\mathrm{D} 4$ to $\mathrm{D} 7$ on right, and $D 1$ to $D 7$ on left. Temperature sense undisturbed. Sense of position normal in fingers and toes. No astereognosis. No ataxia. No Rombergism.

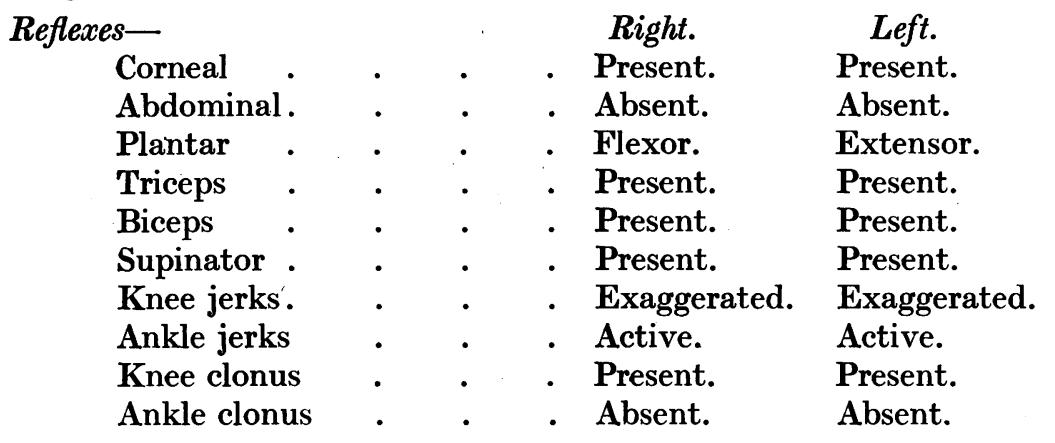

\section{Laboratory Examinations.}

Blood.-January 31, 1922. Wassermann reaction, positive, 4.4.4.4.

March 28, 1922. Wassermann reaction, positive, 4.4.4.4.

Spinal Fluid.-January 31, 1922. Clear, colourless fluid; thirty cells per cubic millimetre ; 5 per cent. large mononuclears. Total protein, 0.025 per cent. Nonne-Apelt, positive. Wassermann reaction, positive, 4.4.4.4.

March 28, 1922. Slightly yellow spinal fluid, with fine coagulum and deposit of red cells ; eleven lymphocytes per cubic millimetre. Total protein, 0.03 per cent.; Nonne-Apelt, positive. Lange gold-sol, 4.5.4.5.5.5.4. 3.2.1. Wassermann reaction, positive, 4.4.4.4.

\section{History since Discharge.}

For over a year the patient was able to get about, but it was noted that marked Parkinsonian attitude and gait developed. He would come into the examining room at a shuffling trot, with rigid body and arms hanging at his 
sides, the fingers moving in a rhythmical tremor. The masklike face completed the picture of paralysis agitans. He grew gradually worse, but there was no marked change until the middle of January, 1924, when the tremor became violent, causing a "jerking in the arms and head" that culminated on February 19 in a sudden comatose condition lasting for thirty-six hours.

On recovering consciousness the patient noticed that the right arm and leg were very weak, but that all tremor had stopped on that side. The tremor continued on the left side for a while, but also ceased at the end of four or more days. Strength in the right arm began to return after about five days.

He was readmitted to hospital on March 3, 1924.

\section{State on Readission.}

The patient lies stolidly in bed, with little expression, practically no motion and little spontaneous speech.

He answers questions pertinently but slowly.

Cranial Nerves.-2. Visual acuity, R. 6/36, L. 6/12. Fields full to rough test; no hemianopia. Fundi show clear discs, of good colour ; ressels some what tortuous.

$3,4,6$. Outward movement of right eye somewhat weak; paralysis of upward movement practically complete. The right eye moves downward and inward fairly well.

There is marked ptosis of the right eyelid. The movements of the left eye are normal. The right pupil is smaller than the left, irregular, and fixed. The left pupil is slightly irregular and reacts to accommodation slightly, but not at all to light.

7. General masklike facies, but no obvious weakness.

Motor System.-Arms: On extending the arms there is observed an unsteadiness from weakness, but no tremor; this weakness is more in the right than the left, and seems to involve the whole arm.

The position of the hands is one of semiflexion with the thumb in. The right grip is weaker than the left. Tonus is increased in all muscles, with slight 'cog-wheel' rigidity to passive movements at the elbow.

Legs: The legs show no tremor; the right is weaker than the left. Muscle tone increased to a less degree than in arms. There is slight general wasting of all the muscles.

Co-ordination cannot be tested, because of weakness. Trunk is rigid as a whole ; head, neck and body move as one piece.

\begin{tabular}{|c|c|c|c|c|}
\hline Reflexes- & & & Right. & Left. \\
\hline Corneal & $\cdot$ & • & - Present. & Present. \\
\hline Abdominal. & $\bullet$ & $\cdot$ & - Absent. & Absent. \\
\hline Plantar & . & • & . Extensor. & Extensor. \\
\hline Triceps & $\cdot$ & . & . Absent. & Present. \\
\hline Biceps & $\cdot$ & . & . Absent. & Absent. \\
\hline Supinator . & $\cdot$ & $\cdot$ & - Present. & Present. \\
\hline
\end{tabular}


Reflexes-

Knee jerks.

Right.

Left.

Ankle jerks

Knee clonus

Exaggerated.

Exaggerated.

Ankle clonus

Active.

Active.

Slight.

Slight.

Absent.

A few jerks.

Sphincters.-Slight dribbling of urine.

Sensory System.-Normal except for diminution of pain sense over both sides of thorax, front and back, practically as described on the former admission, but accurate examination is difficult because of slowness of patient's reactions.

Re-examination, March 6, 1924.

The patient seems more drowsy this morning; his speech is more slurred and indistinct than it was two days ago. During examination he closes his eyes and breathes heavily, going off into a semiconscious condition.

Fields.-No hemianopia can be made out by rough test. Right pupil, $3 \mathrm{~mm}$., irregular ; left, $4 \mathrm{~mm}$., slightly irregular.

There is no tremor at all of the arms, head, legs or trunk. The arms shake a little from weakness in performing movements, and the coordination is not good because of weakness. Grasp is weak in both hands, the weakness being more marked in the right. Both arms are stiff and cog-wheel rigidity is elicited on passive motion. The legs are stiff, with a spasticity that can be broken down by passive movement quite quickly. Both are weak, and the patient is unable to stand. The trunk is stiff, and the patient cannot sit up.

\section{Laboratory Examinations.}

Blood.-March 5, 1924. Wassermann reaction, positive, 4.4.4.3.

Spinal Fluid.-March 11, 1924. Clear; nine lymphocytes per cubic millimetre. Wassermann reaction positive, 4.4.4.4. Nonne-Apelt, strongly positive. Total protein, 0.05 per cent. Lange gold-sol test, 3.3.3.3.4.3.3.4.4.2.

\section{Case 2.-Summary and Comment.}

A carpenter of fifty-nine suffered for four years from lightning pains and unsteady gait, and for three and a half years had a coarse rhythmic tremor of both hands. Examination showed poor intelligence and memory, with depressed mood. Pupils were small and fixed. There was paresis of the right sixth nerve. The right seventh, tenth and twelfth nerves were slightly affected. The face was masklike, the gait slow, and both arms and legs showed rigidity.

Wassermann reaction: Negative in the blood, positive in the spinal fluid.

The diagnosis of tabes seems justifiable in view of the lightning pains, the fixed pupils and the abducens palsy. Involvement of the midbrain is indicated by the Parkinsonian tremor and rigidity. There 
appears to have been a slight cerebral thrombosis causing the symptoms of partial right hemiplegia. It is interesting that on this weakened side the tremor is less marked, making the right arm the more useful. (In case 1, it will be remembered, the tremor ceased entirely after a right hemiplegia of short duration.)

C. D., age fifty-nine, carpenter, was admitted to hospital on July 7 , 1921, with a diagnosis of cerebral syphilis (paralysis agitans and tabes syndrome). He had had syphilis forty years ago.

\section{Present Illasess.}

Four years ago the patient began to have sharp pains in the lower limbs, especially affecting the calves. These pains did not last long at a time but came on frequently, especially after exertion. After a short time they began to occur in the testes also, and in the arms.

About the same time as the pains began he felt that his legs were weak and that he could not walk much. Soon after his lower limbs became shaky and in a short time the shakiness came into the arms also.

\section{State ox Admission.}

Nervous System.-Intelligence poor. Attention normal. Speech, somewhat monotonous and inclined to slur.

Cranial Nerves.-2. Vision: Acuity, R. 6/36, L. 6/36. Fields full. Discs : Right, normal ; left, pale.

$3,4,6$. Pupils equal and regular ; do not react to light ; sluggish reaction on accommodation. Ocular movements : Deficiency of outward movement of right eye ; on looking to extreme right coarse nystagmoid jerkings occur in that eye. Diplopia on looking to right. Internal strabismus right eye.

Sensory System.--Subjective : Sharp attacks of pain in limbs.

Objectice : Cotton wool, normal. Pin prick, diminished in limbs. Vibration sense diminished all over body. Sense of position, fingers poor ; toes normal.

Motor System.-Cpper limbs: Hand grasps poor; other movements fair.

Lower limbs : Power good in all movements. Slight spasticity in muscles of lower limbs.

Abnormal movements. Coarse tremor of outstretched hands. Marked intention tremor. No dysmetria; no ataxia in arms.

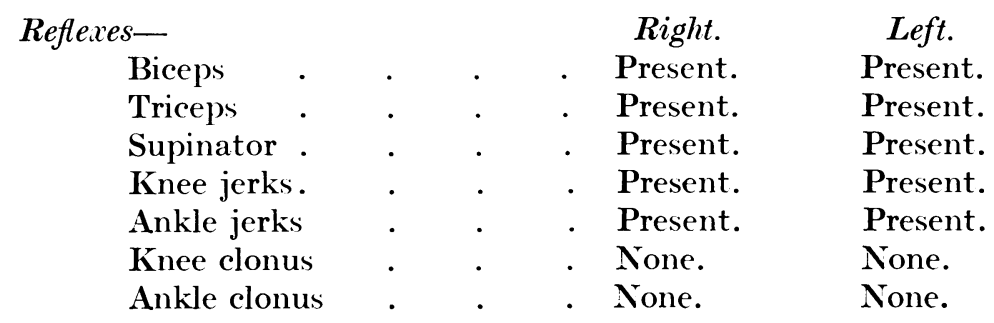




$$
\begin{aligned}
& \text { Reflexes- } \quad \text { Right. Left. } \\
& \text { Epigastric . . . . Present. Present. } \\
& \text { Abdominal. . . . Present. Present, weak. } \\
& \text { Plantar . . . . Flexor. Flexor. }
\end{aligned}
$$

Gait.-Inclined to reel over to right. Swings arms very little. Cannot walk heel and toe. Rombergism present.

\section{Laboratory Examinations.}

Blood.-July 11, 1921. Wassermann reaction, negative.

September 13, 1921. Wassermann reaction, negative.

October 17, 1921. Wassermann reaction, negative.

Spinal Fluid.-July 11, 1921. Slightly yellow fluid with fine web of coagulum; fifty-three cells per cubic millimetre; small and large mononuclears. Albumin, 0.1 per cent. Nonne-Apelt, strongly positive. Wassermann reaction, positive, 4.4.4.4.

September 13, 1921. Clear, colourless fluid; forty-five cells per cubic millimetre. Albumin, 0.05 per cent. Nonne-Apelt, weakly positive. Wassermann reaction, negative.

October 17, 1921. Clear colourless fluid, ten cells per cubic millimetre ; small mononuclear. Albumin, 0.06 per cent. Nonne-Apelt, strongly positive. Wassermann reaction, positive, 4.2.1.0.

Re-examination in Out-patient Department, January 10, 1924.

General.-The physical and mental states are much as previously described.

Cranial Nerves.-2. Visual acuity; fields and fundi show no change since previous examination.

3, 4, 6. Diplopia due to weakness of right external rectus. The pupils are small, irregular and fixed.

5. Diminished appreciation of painful prick on the nose.

7. The face is masklike and expressionless; all movements of the facial muscles are weak and slow, but perhaps weaker on the right than on the left.

8. Hearing poor in right ear.

10. Weakness of right side of soft palate.

12. The tongue is protruded to the right, and shows marked tremor.

Sensory.-No sensory changes made out by objective testing, except a slight hypæsthesia to all stimuli throughout, and marked hypalgesia to pin prick on the nose, forearm and hands.

Subjectively the patient complains of 'stabbing pains' in the shins, the inner side of the arms, and the dorsal aspects of the hands.

Motor.-There is no muscular wasting. Tone is increased to give ' cogwheel 'rigidity in the arms, and slight spasticity in the legs. No paralysis, but the right arm is weak. In both arms there is a steady rhythmic tremor, but this is more conspicuous on the left. The left hand shows a regular tremor while at rest and supported, with the typical 'pill-rolling' motions of the fingers and thumb. When the patient attempts to use the hand the 
tremor is at first inhibited and then increased, so that he performs the fingerto-nose test with marked increase of the tremor. In the right hand these phenomena are present, but to a less degree.

\begin{tabular}{|c|c|c|c|c|}
\hline Reflexes- & & & Right. & Left. \\
\hline Biceps & $\cdot$ & • & Active. & Active. \\
\hline Triceps & . & $\cdot$ & . Present. & Present. \\
\hline Supinator . & . & . & . Active. & Active. \\
\hline Knee jerks. & . & . & . Active. & Active. \\
\hline Ankle jerks & - & . & . Weak. & Present. \\
\hline Abdominal & . & . & . Weak. & Active. \\
\hline Plantar & . & . & . Flexor. & Flexor. \\
\hline
\end{tabular}

Since the former examination the changes consist principally of more facial weakness, more weakness of the right side with depressed right abdominal reflexes, more lightning pains and more tremor on the left side.

\section{Case 3.-Summary and Comment.}

A journalist of fifty-six was admitted to hospital because of lightning pains, from which he had suffered for four years.

At the age of twenty he had syphilis, for which he was given a six months' course of treatment. He remained quite well until the age of fifty-two, when dysuria developed and a diagnosis of tabes dorsalis was made. Pain and unsteadiness of the legs began three years later, and afterwards tremor in his hands, slow speech, and mental confusion.

On admission to the National Hospital his tremor, speech, facies and posture indicated Parkinson's disease, while the mental state, the cranial nerve palsies and fixed irregular pupils, with absent knee jerks and areas of hypæsthesia, suggested the diagnosis of taboparesis. The Wassermann reaction was positive in both the blood and cerebrospinal fluid.

This is obviously a case of neurosyphilis of the taboparetic class, but extensive involvement of the basal ganglia and midbrain is indicated by the tremor, the unequal fixed pupils, the weakness of all the ocular movements, especially upward movement, and the Parkinsonian facies and posture.

E. F., age fifty-six, journalist, was admitted to hospital on August 3, 1920, with a diagnosis of taboparesis and paralysis agitans. He had had syphilis thirty-six years previously.

\section{Present Illness.}

Patient was quite healthy until 1916 and was doing war work when he first noticed that he could not hold or pass his water easily. The difficulty increased and he began to suffer from nocturnal incontinence.

In December, 1919 ' excruciating pain' began in the right thigh and leg, 
and continued until the end of January, 1920. He could not get about because the legs gave way, but they were not unsteady and his walking was not worse at night.

About this time he noticed a tremor in his hands, while his wife commented on the fact that his speech had become much slower.

Towards the end of January he went back to work again, but he found that he became very tired in the afternoon and had great difficulty in walking ; sometimes he could hardly get home.

\section{State ox Admission.}

Patient looks older than fifty-six. Has a rather fixed expression.

Cerebration is slow and memory not good. When asked if he had any pain he said "No" on several occasions and then proceeded to give a long description of his tabetic pains.

Speech slow and rather like that of Parkinson's disease.

Cranial Nerves. - 2. Acuity, normal. Fields normal to rough test. Fundi clear ; discs perhaps a little pale.

3, 4, 6. Pupils large and fixed. Left almost circular; right is irregular.

All movements are slightly defective in all directions, especially upwards, and towards the end of the movement paretic nystagmoid jerks develop. Convergence is also poor though present. Left palpebral fissure is slightly larger than the right. Left lid lags a little on looking downwards.

7. Slight weakness of left orbicularis ; tremor of the face on contraction.

10. Palate moves slightly over to the left.

12. Tongue protruded to the right, slightly wasted in the right half, and it is tremulous and flabby. Trombone tremor.

Sensory System.-Objective : Diminution to pain all over body except the neck and outer face. Diminution to touch in the lower limbs below the knee. Vibration sense is diminished from iliac crests downwards, left more than right. There is some loss of sense of position in the lower limbs.

Motor System. - Some general muscular wasting, but it is decidedly marked in the small muscles of both hands, left more than right. Hypotonia is not apparent. In the upper limbs there is a coarse flexor-extensor tremor, with intention tremor in the left finger-to-nose test. Ordinary movements are slow and deliberate and in the lower limbs there is some ataxia, left more than right, and some tremor.

Reflexes.-Arm jerks : Biceps and supinator, much exaggerated ; triceps, normal.

Epigastric : Absent.

R. hypogastric just present; L. absent.

Knee jerks : Absent.

Ankle jerks : L. absent ; R. present.

Plantars : L. flexor; R. Babinski response, with occasional flexion.

Gait.-The gait is slow. No dragging of feet and no unsteadiness. No retropulsion or propulsion. No Rombergism.

Sphincters.-Difficulty in passing water. Incontinence at night. Overflow incontinence due to mechanical causes. 


\section{Laboratory Examinations.}

Blood.-August 4, 1920. Wassermann reaction, positive, 4.4.4.4.

Spinal Fluid.-August 4, 1920. Clear, colourless fluid ; sixty-nine cells per cubic millimetre ; almost all small lymphocytes, but a few large mononuclears and plasma cells. Albumin, 0.03 per cent. Nonne-Apelt, strongly positive. Wassermann reaction, positive, 4.4.4.4.

\section{Case 4.-Summary and Comment.}

A painter of fifty-four, who presented no history or sign of plumbism, had syphilis nineteen years ago, inadequately treated. For about seven
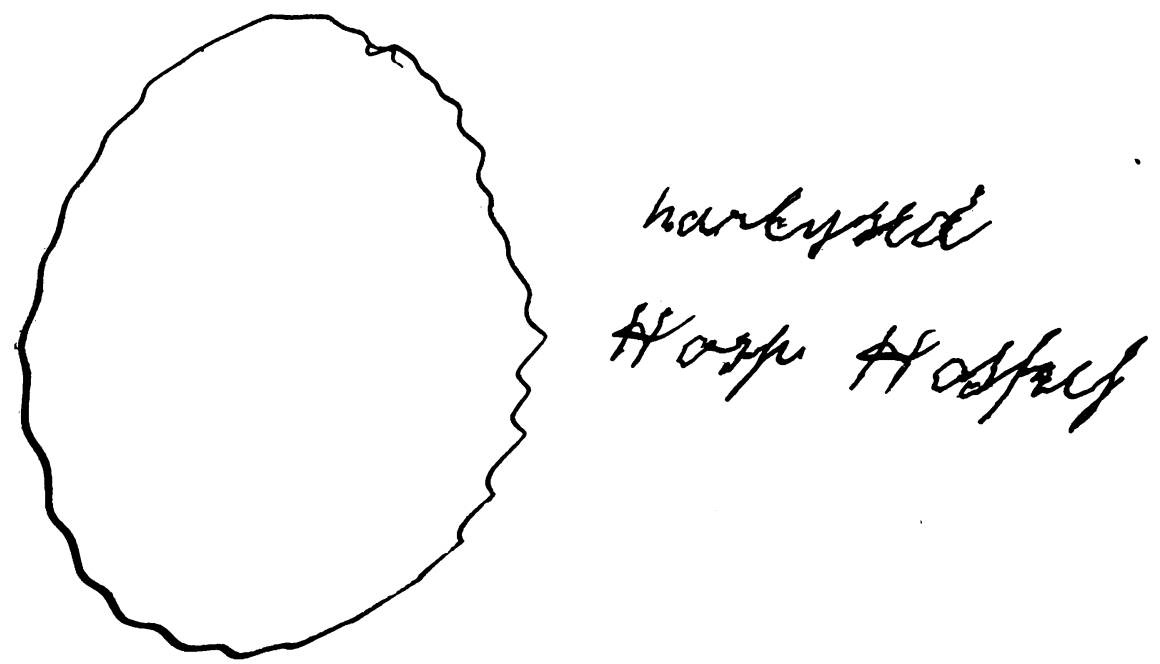

Fig. 1.-CaSe 4. An attempt to draw a circle with the right hand, and to write the words 'paralysed' and 'Hospital.'

years he had had tremor in the right hand, and for a shorter time in the left. During this period there was pain in the arms, and more recently irritability, insomnia and headache.

Physical examination discovered absent knee and ankle jerks, with Romberg's sign of ataxia. The tremor was present in both hands, but more marked in right. It was of mesencephalic type : coarse and rhythmic, absent when the limb was completely at rest, elicited by extending the arms, but not increased by volitional movements. (Fig. 1.)

There were no symptoms otherwise of the paralysis agitans syndrome. The pupils were unequal, irregular, and reacted sluggishly to light but well on convergence. Wassermann reaction negative in blood and C.S.F.

Clinically this case seems clearly to be one of tabes, with a history of syphilis, pain, typical pupils and absent tendon reflexes. The tremor 
is unusual, but being of a type associated with lesions of the red nucleus, the case fits well into our category of syphilitic mesencephalitis.

The laboratory examinations, however, do not bear out the clinical diagnosis of syphilis. It is, of course, well known that tabes may become inactive and spontaneously die out, and this would seem to be the best explanation of the symptoms in this long-standing case, a supposition perhaps somewhat substantiated by the slight abnormalities of the spinal fluid. Nevertheless it must be kept in mind that lead poisoning may closely simulate tabes, and the patient being a painter makes the diagnosis of plumbism a possible one. In either case we seem to be dealing with a mesencephalitis.

G. H., age fifty-four, was admitted to hospital on March 11, 1924, because of tremor.

\section{Previous Illnesses.}

Gonorrhœa and chancre at thirty-five. Was treated for syphilis in a London hospital, but only carried on treatment for a couple of months.

\section{History of Present Illness.}

For six or seven years the patient has had 'shakiness' of both hands. In 1919 he fell off a staging, was not unconscious after the fall, and was in hospital for a few hours only, but immediately after this the tremor of his hands increased rapidly. At times his legs have felt shaky, but there has never been an obvious tremor like that in the hands. There has been no difficulty in walking either in the light or in the dark, nor has there been any weakness of the legs.

For six or seven years he has had attacks of pain in the wrists and hands. He describes the pain as an aching cramp which comes on gradually, reaching a maximum in five or six minutes, and then passes off. These are severe and have at times caused him to stop work. There is no history of 'lightning pains.' He occasionally has headache, frontal, vertical and occipital ; this has been a more prominent symptom during the last three or four months.

Twice last year there were transient attacks of blurred vision.

Mentally he has been depressed, nervous and irritable. He says he has recently "lost his self-control." He sleeps poorly at night, and lies in bed wide awake, feeling " all of a shake."

He has worked right up to the time of his admission to the hospital whenever there was a painting job, but the work has not been regular. He has never had any colic or unequivocal symptoms of lead poisoning.

State on Admission.

A well-developed and well-nourished man.

Nervous System.-From the mental standpoint the patient appears to be a good witness, and mentally alert. The only thing noted is a tendency to hypochondriasis, and a willingness to be examined that betrays anxiety.

Cranial Nerves.-2. Fields normal to rough test. Fundi : Both show deep pits, but no pallor. 
$3,4,6$. The movements of the eyes are full and normal. No nystagmus. The pupils are unequal and irregular, the right being $5 \mathrm{~mm}$. in diameter, and the left $3 \mathrm{~mm}$. Both react only slightly and sluggishly to light, but contract briskly on convergence.

7. There is no weakness, but the whole face appears rather flat and expressionless.

12. Tongue is protruded in the mid-line with slight tremor, but at rest in the mouth there is no tremor.

Sensory.-Slight diminution in appreciation of vibration and position in both feet. No areas of analgesia or anæsthesia. Romberg's sign positive.

Motor.-There is no paralysis of any muscle group, and no muscular atrophy. The tone of the muscles in the arms and trunk is normal, but in the legs it appears to be decreased.

Arms.--Tremor is absent in the arms when they are completely at rest and supported, but when even one finger is unsupported, and then put on a slight muscular tension, a rhythmic tremor is developed. This can be increased and elicited in both hands and wrists by asking the patient to extend his arms.

A slight flexion-extension movement is seen in the finger and wrist joints, with an additional pronation-supination element in wrist and forearm.

The whole complex comprises a coarse rhythmic tremor, well sustained and slightly sinuous. Causing the patient to grip strongly with the left hand increases this tremor conspicuously in the right hand: gripping with the right hand has a similar but less marked effect on the left. Carrying out intended actions, such as performing the finger-to-nose test, increases the tremor slightly. In all aspects it is somewhat more marked on the right than on the left.

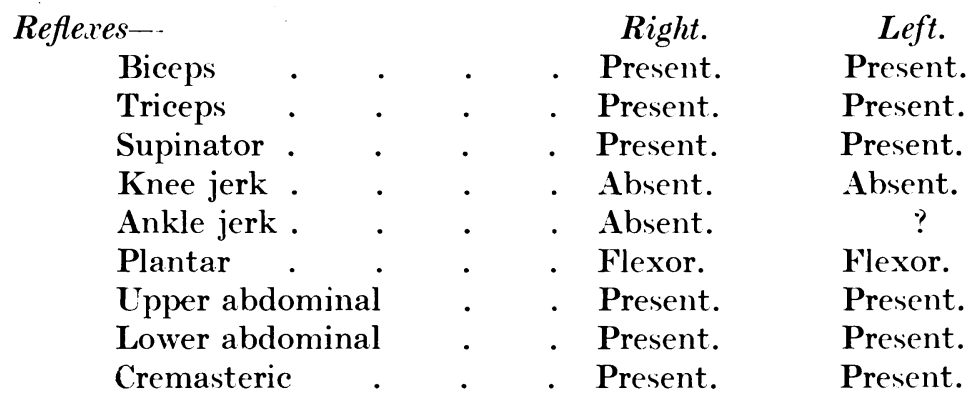

\section{Laboratory Examinations.}

Blood.-March 18, 1924. Smear shows normal red cells with no punctate basophilia. Wassermann reaction, negative.

Spinal Fluid.-March 18, 1924. Cell count of four lymphocytes per cubic millimetre. Total protein, $0.0+$ per cent. Nonne-Apelt, weakly positive. Lange colloidal gold, 0.0.0.1.2.1.0.0.0.0. Wassermann reaction, negative. 


\section{SUMMARY.}

Four cases are presented as evidence to support the thesis that Argyll Robertson pupil and tremor occurring in the same case of syphilis are not merely coincidental, as held by most former investigators of the subject. Rather does this combination (with its various elaborations such as oculomotor palsy and rigidity) indicate an incidence of the syphilitic process on the midbrain, a true syphilitic mesencephalitis.

\section{REFERENCES.}

1 Souques and Trétiakoff, Soc. méd. des hôp. de Paris, 1920, xliv, 1027.

2 LHERMTTTE and CoRNIL, Rev. neurol., 1921, xxviii, 587.

3 Souques, Rev. neurol., 1921, xxviii, 534.

4 Forx and Nicolesco, L'Encéphale, 1923, xviii, 553.

5 Eshner, Am. Jour. Med. Sci., 1909, cxxxviii, 729.

6 WILson, Jour. of Neurol. and Psychopath., 1921, ii, 1.

7 NAtTrass, Jour. of Neurol. and Psychopath., 1923, iv, 162.

8 voN MonAkow, Gehirnpathologie, 1905, 970,982.

9 Holmes, Brain, 1904, xxvii, 327.

10 WiLson, Rev. neurol., 1921, xxviii, 609.

11 Wertheim-Salomonson, Neurol. Centralb., 1900, xix, 741.

12 URECHIA, Rev. neurol., 1921, xxviii, 584.

13 Melda and Katz, Jour. Nerv. Ment. Dis., 1924, lix, 225.

14 Ewald, Deut. Arch. f. Klin. Med., 1877, xix, 591.

15 KNESSNen, Arch. f. Psychiat., 1878, viii, 443.

16 HeImanN, "Graduation Thesis," Berlin, 1888.

17 PlaczeK, Deut. med. Woch., 1892, 632.

18 WeIL, Neurol. Centralb., 1898, xvii, 713.

19 Hess, Neurol. Centralb., 1900, xix, 583.

20 Rhein, Jour. Amer. Med. Assoc., 1902, xxxix, 1632.

${ }^{21}$ KrabBe, Zeit. f. d. g. Neurol. u. Psychiat., 1912, ix, 571.

22 BRUns, Neurol. Centralb., 1904, xxiii, 978.

23 CAMP, Jour. Nerv. Ment. Dis., 1914.

24 BYchowski, Neurol. Centralb., 1904, xxiii, 786.

25 HOLBRoN and LERI, Rev. neurol., 1923, xi, 547.

26 DE MASSARY, Rev. neurol., 1922, xxix, 1368.

27 ARCHARD and Rouillard, Soc. méd. des hôp. de Paris, 1921, xlv, 130. 